\title{
Transforming the theatre of surgery
}

\section{A Commotion in the Blood: Life, Death and the Immune System} by Stephen S. Hall

Holt: 1997. Pp. 457. \$36

\section{Fred S. Rosen}

At the beginning of this century, William B. Coley was one of the leading cancer surgeons in New York City. Born a Connecticut yankee and reared in impoverished circumstances with a stern Wesleyan morality, he eventually found his way as an undergraduate to Yale University and thence to the Harvard Medical School - an educative sequence that only infrequently leads to the anticipated result. He then went to New York City where he rapidly developed an interest in the treatment of malignancies.

He observed the complete regression of a cancer in a patient who had recently been infected with the skin disease erysipelas, and this prompted him to make culture filtrates of Streptococcus pyogenes, the microbe that causes erysipelas, for injection into other cancer patients; he subsequently added Serratia marcescens to the brew that came to be called Coley's toxin. There were sporadic and tantalizing successes with Coley's toxin.

Coley wisely befriended the Rockefellers and Huntingtons and effectively tapped into their charitable instincts. This, ultimately, was a critical factor in the creation of the vast biomedical emporium on the East River at 68th street in Manhattan. James Ewing, of the eponymous bone cancer, Ewing's sarcoma, and head of pathology at the Memorial Hospital, became a strong advocate of Röntgen's discovery of X-rays in the treatment of malignancies, and so became the nemesis of Coley's toxin. The monumental conflict between these giants of surgery and pathology is a fascinating story in the history of medicine and is well told in the best part of this book.

In any event, Coley's toxin was never standardized or subjected to proper scientific scrutiny and interest in it almost completely died with him in 1936. Coley was at heart a surgeon, a profession with a strong theatrical element that is basically in conflict with the painstaking details of data-gathering requisite for good science. Ultimately, proper scrutiny of Coley's toxin proved that the cancer-shrinking component was endotoxin or lipopolysaccharide in the bacterial filtrate.

Endotoxin is a potent vehicle for eliciting the synthesis and secretion of inflammatory molecules such as interferons, interleukins2 and -12 and tumour necrosis factor- $\alpha$. How each of these molecules was discovered and the exciting race to clone the genes encoding them are recounted in gripping journalistic style in this book. The cast of

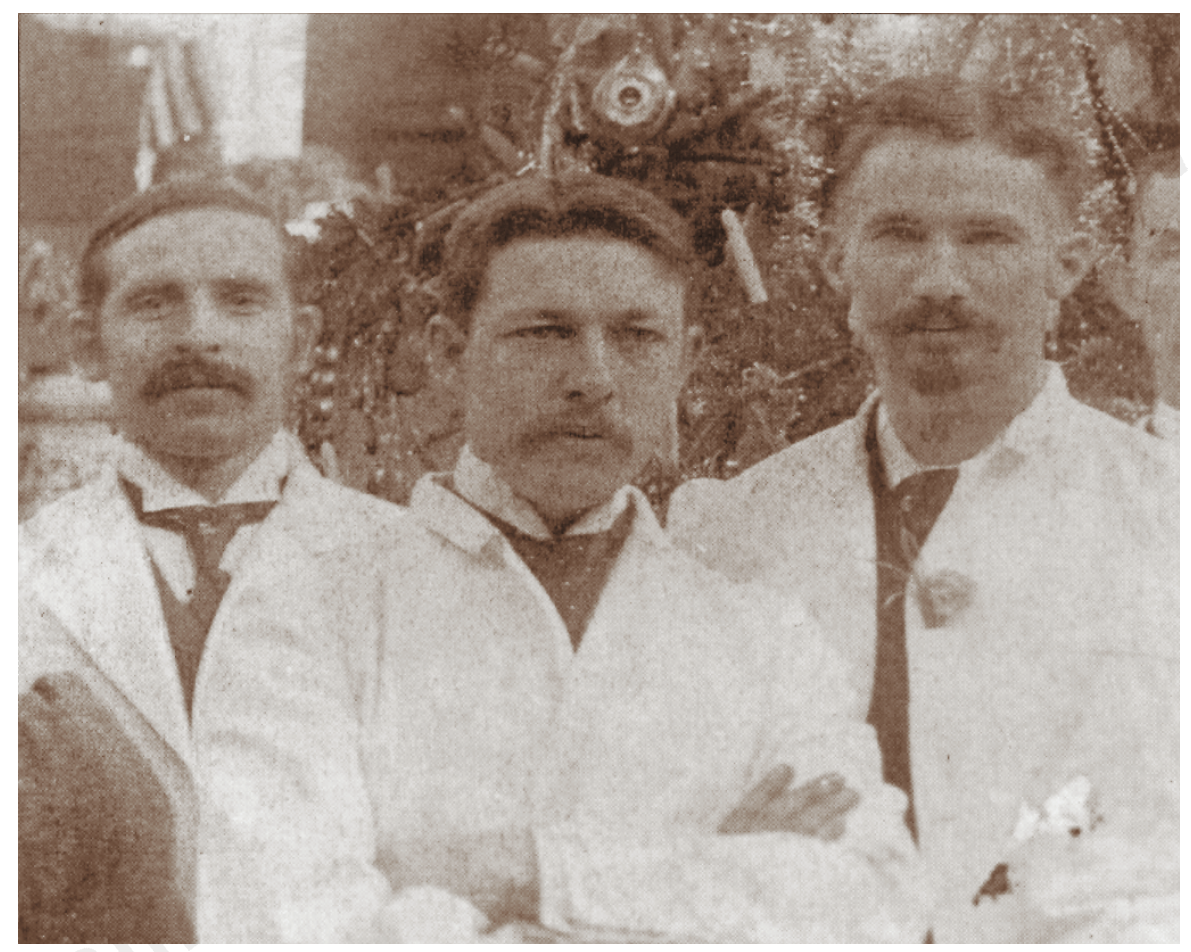

Coley (centre) in December 1892, one month before the first use of Coley's toxin.

characters involved leads to the inevitable conclusion that science is not a gentlemanly profession in the latter half of the twentieth century.

And there now enters another surgeon, Dr Steven Rosenberg, who exploits the clinical use of these molecules to treat cancer patients and elevates the theatre of surgery to hitherto unknown heights. Like Coley, he is well educated and has tapped into the vast resources not of the robber barons but of the US taxpayers who support the National Institutes of Health. His personalized war against cancer arouses sympathy and alarm. Torn between compassion for the needy and very sick patients he is treating and "careerist entrepreneurship", he does not emerge from the book as a model of how to overcome our frustration with the very limited progress in cancer therapy in recent years.

It is unfortunate that these therapeutic manoeuvres from Coley to Rosenberg have been called immunotherapy. They are really phlogistic therapies, which incite inflammation in a nonspecific manner, and have at best to do with innate and not adaptive immunity. The work of Thierry Boon in Belgium, which is also detailed in this book, has recently been heading in the direction of immunotherapy, proprement dit, as he defines tumour-specific antigens that may evoke future therapeutic possibilities.

A number of small peccadilloes mar this book in the interchangeable use of toxin and vaccine and other loose word usage. The
Royal Experiment - the smallpox inoculation of the children of Frederick, Prince of Wales, which the royal physician, Sir Hans Sloane, described as "raising such a commotion in the blood" - did not occur in 1721, nor is the New England Journal of Medicine a publication of the Harvard Medical School or the Massachusetts General Hospital.

"Careerist entrepreneurship" was a choice term used in an upbeat review of this book by Roy Porter in The New York Times. A Commotion in the Blood is a wonderful book for lay readers who want to know more about current biomedical science. Unlike James Gleick's Genius or Dava Sobel's Longitude, two recent popular books for the lay reader that give no real scientific insight into their subject matter, A Commotion in the Blood is replete with scientific details recounted in very comprehensible prose. It is indeed a good read for the aficionados of The New York Times, and even of the London Times, as well as any surviving readers of the Boston Evening Transcript, so maligned by T. S. Eliot.

Twenty years ago a godson of mine developed a very malignant lymphosarcoma. The sage doctors gave him six months to live. $\mathrm{He}$ is now well, prosperous and thriving. He never received any immunotherapy. Some day we will understand these still mysterious medical events.

Fred S. Rosen is at the Center for Blood Research, Warren Alpert Building, 200 Longwood Avenue, Boston, Massachusetts 02115, USA. 